\title{
Large-scale integration of single-walled carbon nanotubes and graphene into sensors and devices using dielectrophoresis: A review - ERRATUM
}

Brian R. Burg and Dimos Poulikakos

doi: 10.1557/jmr.2011.186, Published by Cambridge University Press, 4 July 2011.

The authors' affiliation was incorrect as printed. The institution was not included.

The correct affiliation is as follows:

Laboratory of Thermodynamics in Emerging Technologies, Department of Mechanical and Process Engineering, ETH Zurich, 8092 Zurich, Switzerland
The publisher regrets the error.

\section{REFERENCE}

Brian R. Burg and Dimos Poulikakos: Large-scale integration of singlewalled carbon nanotubes and graphene into sensors and devices using dielectrophoresis: A review. J. Mater. Res. 26(13), 1561 (2011). 